Ege Tıp Dergisi / Ege Journal of Medicine 2016;55(2):55-58

\title{
Bir üniversite hastanesinin doğum polikliniğine başvuran gebelerde gestasyonel diabetes mellitus prevalansı
}

The prevalence of gestational diabetes mellitus in pregnants who applied to the maternity outpatient clinic of a university hospital

Gülşah Balık ${ }^{1}$ Serap Baydur Şahin ${ }^{2} \quad$ Yeşim Bayoğlu Tekin ${ }^{1} \quad$ Şenol Şentürk ${ }^{1} \quad$ Mehmet Kağıtcı $^{1}$

Figen Kır Şahin ${ }^{1}$

${ }^{1}$ Recep Tayyip Erdoğan Üniversitesi Tıp Fakültesi, Kadın Hastalıkları ve Doğum Anabilim Dalı, Rize, Türkiye

${ }^{2}$ Recep Tayyip Erdoğan Üniversitesi Tıp Fakültesi, İç Hastalıkları Anabilim Dalı, Rize, Türkiye

\section{Öz}

Amaç: Gestasyonel diabetes mellitus (GDM) gebeliğin önemli bir komplikasyonudur. Fetal ve maternal morbidite ve mortaliteye neden olur. GDM taramasında tek ve iki basamaklı tarama testleri kullanılabilir. Bu çalışmanın amacı bir üniversite hastanesinin doğum polikliniği'ne başvuran gebelerde GDM prevalansının araştırılmasıdır. Gereç ve Yöntem: Obstetrik kliniğimize 01.01.2012 ve 31.12.2013 tarihleri arasında başvuran 24-28 gebelik haftasındaki gebeler retrospektif olarak incelendi. Amerikan Diabet Birliği kriterlerine göre tek basamaklı tarama testi ile diabet taraması yapılan hastalar çalışmaya dahil edildi. GDM prevalansı hesaplandı.

Bulgular: GDM prevalansı \% 24.8 (383/1536) olarak tesbit edildi. GDM olan ve olmayan hastaların yaş ortalaması sırasıyla $31.37 \pm 6.56$ ve $28.28 \pm 5.71$ olarak bulundu. Her iki grubun yaş ortalamaları arasındaki fark istatistiksel olarak anlamlı idi $(p=0.00)$.

Sonuç: Gebe grubumuzda GDM prevalansı yüksek bulundu. İleri anne yaşı GDM için bir risk faktörüdür. Tek basamaklı tarama testi ile GDM prevalansının yüksek çıktığına inanmaktayız. Tek basamaklı tarama testi yeniden gözden geçirilmelidir.

Anahtar Sözcükler: Gestasyonel diabetes mellitus, prevalans, gebelik.

\section{Abstract}

Aim: Gestational diabetes mellitus (GDM) is an important complication of pregnancy. It causes fetal and maternal morbidity and mortality. One or two step screening tests can be used for screening of GDM. The goal of this study is to investigate the prevalence of GDM in women who applied to the maternity outpatient clinic of a university hospital. Materials and Methods: Pregnant women who presented to our obstetrics clinic between 01.01.2012 and 31.12.2013 and those who were at their 24th-28th weeks were investigated retrospectively. The patients who were screened with one step screening and those whose diabetes screening were done according to American Diabetes Association criteria were included in this study. The prevalence of GDM was calculated.

Results: The prevalance of GDM was $24.8 \%$ (383/1536). The mean age of participants with and without GDM were respectively $31.37 \pm 6.56$ and $28.28 \pm 5.71$. The differences between the mean ages of both groups were statistically significant $(p=0.00)$.

Conclusion: The prevalence of GDM was found high among our antenatal population. Advanced maternal age is a risk factor for GDM. We believe that with one step screening test, the prevalence of GDM is high. The one step screening test should be revised.

Keywords: Gestational diabetes mellitus, prevalence, pregnancy.

\section{Giriş}

Gestasyonel diabetes mellitus (GDM) gebelik sırasında başlayan veya tanımlanan karbonhidrat intoleransıdır $(1,2)$. Gebeliğin en sık görülen tıbbi komplikasyonudur.

Yazışma Adresi: Gülşah Balık

Recep Tayyip Erdoğan Üniversitesi Tıp Fakültesi, Kadın Hastalıkları ve Doğum Anabilim Dalı, Rize, Türkiye

Geliş Tarihi: 25.12.2014 Kabul Tarihi: 11.03.2015
GDM genellikle ikinci trimesterde artmış insülin direncinin bir sonucu olarak gebeliğin 24 . ve 28. haftaları arasında ortaya çıkar (3). GDM hem anne ve hem fetus için zararlı olmakta ve beş kat artmış perinatal morbidite ve mortalite ile ilişkilidir. Bu nedenle GDM'nin olası en erken zamanda tanınması ve tedavi edilmesi maternal ve fetal riskleri azaltacaktır. GDM'nin bir komplikasyonu olarak oluşan fetal makrozomi operatif doğum, omuz distosisi ve doğum travması gibi ikincil komplikasyon 
oranlarındaki artışa neden olmaktadır. Buna ek olarak ölü doğum, erken doğum, düşük yapma ve doğum kusurları diğer komplikasyonlardır. Kötü maternal glisemik kontrol \%42.9 gibi yüksek oranda perinatal mortalite ile ilişkilidir (4). GDM olan kadınlarda doğumdan sonraki 5-10 yıl içinde \%35-60 oranda diyabet gelişme riski vardır (5).

Ülkemiz gibi gelişmekte olan ülkelerde ve tüm dünyada DM ve GDM'un görülme sıklığı artmaktadır. GDM prevalansı toplumlara ve uygulanan tanısal kriterlere göre değişir. Gestasyonel diyabetin toplumdaki sıklığı net olarak bilinmemektedir. Literatürde her toplumun kendi özelliklerine ve kullanılan tanı kriterlerine göre görülme sıklığı değişmekte ve bu oran \% 1 ile \% 18.9 arasında bildirilmektedir (6). ABD'de ülkenin farklı bölgelerinde Irk, diyet, ailede diyabet öyküsü, beyaz olmayan ırk ve sosyoekonomik durum ve obezite gibi birçok faktöre bağlı olarak \%7-18 gibi geniş bir aralıkta GDM prevalansı bildirilmektedir (7). Amerikan Diyabet Birliği (ADA) GDM sıklığını \% 18 olarak bildirmiştir (8).

Gebelerin GDM taraması rutin antenatal bakımın önemli bir parçasıdır. Amerikan Obstetri ve Jinekoloji Derneği (ACOG) tüm gebelerin GDM için taranmasını önermektedir. GDM'nin mümkün olduğunca en erken zamanda tanınması ve komplikasyonların önlenmesi önemlidir. Gebelerde GDM'yi tespit etmek için tek ve iki basamaklı olarak yapılan iki ayrı tarama yöntemi bulunmaktadır. Bu iki farklı tarama testi kullanımı farklı GDM prevalansı sonuçlarına neden olmaktadır. Tek basamaklı tarama testi (75 g OGTT) gebelerin GDM olarak iki-üç kat daha fazla tanı almasına neden olmaktadır $(5,9)$.

GDM için en iyi tarama yöntemi konusunda ulusal ve uluslararası bir fikir birliği yoktur. Bu nedenle bu çalışmada Doğu Karadeniz Bölgesinde, üçüncü basamak bir hastanede kadın doğum polikliniğine başvuran gebelerde yapılan tek basamaklı tarama testi ile GDM sıklığının ne kadar olduğunu belirlemeyi araştırdık.

\section{Gereç ve Yöntem}

Kliniğimiz obstetri polikliniğine 1 Ocak 2012 ve 31 Aralık 2012 tarihlerinde 24-28 gebelik haftası arasında başvuran tek basamak test ile GDM taraması yapılmış 1536 gebenin verileri retrospektif olarak incelendi. Gebelerin yaşları kaydedildi.

Tek basamaklı tarama testinde tanı koymak için ADA kriterleri kullanıldı. GDM kriterleri normal değer: Açlık $<92 \mathrm{mg} / \mathrm{dL} ; 60 \mathrm{dk}<180 \mathrm{mg} / \mathrm{dL} ; 120 \mathrm{dk}<153 \mathrm{mg} / \mathrm{dL}$ olup bu değerlerden bir veya birden çok yüksek değer olması halinde test pozitif kabul edildi (7). Tek basamaklı tarama test sonuçlarına göre GDM prevalansı belirlendi. Gebelerin yaşları ve tek basamaklı tarama test sonuçları karşılaştırıldı.

\section{İstatistiksel Değerlendirme}

Verilerin değerlendirilmesinde SPSS 17.0 programı kullanıldı. GDM prevalansı ve hastaların yaş ortalaması değerlendirildi. Mann Whitney $U$ testi ile istatistiksel analiz yapıldı. $p<0.05$ değeri istatistiksel olarak anlamlı kabul edildi.

\section{Bulgular}

Tek basamaklı tarama testinde ile GDM taraması yapılmış gebelerin 378'inde (\%24.6) GDM tesbit edildi. Tarama yapılan 1536 gebenin yaş ortalaması $27.98 \pm 5.89$ (yaş aralığı 15-49 yaş) idi. GDM olan gebelerin yaş ortalaması $29.94 \pm 6.19$, GDM olmayan gebelerin yaş ortalaması ise $27.34 \pm 5.65$ olarak tesbit edildi. Her iki grubun yaş ortalamaları arasındaki fark istatistiksel olarak anlamlı idi $(p=0.00)$.

\section{Tartışma}

Tüm dünyada GDM vakalarının sayısı gün geçtikçe arttığı düşünülmekte ve GDM için değişebilir risk faktörleri ile ilgili karar vermede epidemiyolojik veriler yetersiz kalmaktadır. GDM prevalansı ırk, beslenme, obezite ve sosyoekonomi gibi birçok faktörden etkilenmektedir. Asyalı kadınlarda yüksek oranda GDM görülmesi yeni araştırmalara intiyaç olduğunu göstermektedir (10). Ülkemizin farklı bölgelerinde yapılan çalışmalarda iki basamak tarama testi kullanılan gebelerde GDM prevalansı \%3.1, \%8.6 ve \%8.9 gibi farklı değerlerde bulunmuştur (11-13). Ülkemizde yapılan bir çalışmada hem tek basamaklı hemde iki basamaklı tarama testi ile GDM prevalansını araştırmışlar. Bu çalışmada tek basamaklı tarama testi ile GDM prevalansı \%14.5, iki basamaklı tarama testi kullanıldığında GDM prevalansı \%6 olarak tespit edilmiştir. Görülmektedirki iki tarama testi arasındaki fark iki kattan daha yüksek orandadır (14). Biz bu çalışmada uyguladığımız tek basamaklı tanı yöntemi ile GDM prevalansını \% 24.5 olarak bulduk.

Ülkemizde olduğu gibi GDM tanısını koymada Avrupa, $A B D$ ve diğer birçok ülkede farklı yaklaşımlar uygulanmakta ve tek bir görüş birliği olmadığı bilinmektedir. International Association of Diabetes in Pregnancy Study Group (IADPSG) yaptığı açıklamada tek basamaklı yaklaşımla GDM prevalansının \%15-20 gibi yüksek bir oranda bulunduğunu bunun iki basamaklı testtin yaklaşık 2-3 katı oranda olduğunu, aksine iki basamaklı tarama testinde bu oranın \%5-6 olarak daha az olduğunu belirtmişlerdir. Ayrıca bu çalışmada IADPSG eşik değerlerine göre GDM olan hastalar ile GDM olmayanların gebelik prognozlarının farklı olmadığı tespit edilmiştir. Bu nedenle IADPSG iki basamaklı tarama testine devam edilmesine karar vermiştir $(3,15)$. AGOC ve ADA iki basamaklı taramaya devam edilmesini tavsiye etmektedir $(5,7)$. Buna karşılık Avrupa Diabetik Gebelik Çalışma Grubu ve Dünya Sağlık Örgütü, 
İngiltere'de National Institute for Health and Clinical Excellence $75 \mathrm{~g}$ test kullanılmasını önermektedir $(17,18,8)$. American National Institutes of Health uzmanları ise Mart 2013'de yayınladığı kararda iki aşamalı tanı testlerine devam edilmesini (50 g glukozlu ön tarama testi ve arkasından $100 \mathrm{~g}$ glukozlu 3 saatlik OGTT) önermişlerdir (19). Ülkemizde Türk metabolizma ve Endokrinoloji Derneği, iki basamaklı testin yapılmasını önermektedir (20). GDM tanı ve tarama testlerindeki farklı yaklaşımlar için birçok neden sözkonusudur. GDM komplikasyonlarının ciddiyeti, özellikle perinatal mortaliteye neden olması, epidemiyolojik ve kültürel farklar ve lokal uygulama alışkanlıkları tanı ve taramadaki farklı yöntemlere neden olmaktadır. GDM taramasında ülkemizde her iki tarama testi kullanılmakta ve bunun sonucu olarak GDM sıklığını araştıran çalışmalar birbirinden farklı sonuçlar vermektedir. Son yıllarda uygulanmaya başlanan tek basamaklı tanı testi ve kullanılan son kriterler ile GDM tanısı koymanın çok kolay olması, bunun sonucu olarak GDM tanısı alan gebe sayısının çok artması bu durumun ekonomik ve emosyonel sorunları artırabileceği aşikardır. Bu nedenle tek ve iki basamaklı tarama yöntemlerinin karşılaştırılacağı klinik prospektif çalışmalara intiyaç vardır. Günümüzde birçok sağlık kurumu ve Türk Diyabet Derneği kanıta dayalı bulgular elde edilene kadar iki basamaklı (50 g glukozlu ön tarama testi ve ardından $75 \mathrm{~g}$ glukozlu OGTT) tanı yaklaşımına devam edilmesini benimsemişlerdir (20).

GDM etnik nedenlere bağlı olarak belli toplumlarda neden arrı̆̆ı çok iyi anlaşılmamıştır. Gelişmekte olan ülkelerde GDM prevalansının artmasında kentleşmenin artışı, fiziksel aktivitenin azalması, diyet alışkanlıklarının değişmesi ve artan obezite sorumlu tutulmaktadır (21). Diğer bir durum son yıllarda GDM prevalansının maternal yaştaki artışla ilgili olarak arttığı ileri sürülmektedir. GDM görülme sıklığını etkileyen önemli bir faktörde anne yaşıdır. Yapılan çalışmalarda 25 yaş altı kadınlarda insidans \%0.4-0.8 iken, 25 yaş üstü grupta bu oran \% 4.3-5.5 olarak bulunmuştur $(8,19)$. Çalışmamızda literatürü destekler biçimde yaşla birlikte GDM görülme sıklığının arttığını bulduk. Diğer önemli risk faktörü obezitedir. Ancak çalışmamızın bir sınırlaması olarak gebelerin vücut ağırlıklarının bilinmemesi ve obezite varlığının tartışılamaması söz konusudur.

Çalışmamızın diğer bazı sınırlamaları bulunmaktadır. Çalışma grubumuzdaki gebeler $75 \mathrm{~g}$ OGTT ile taranması sonucu GDM prevalansı oldukça yüksek oranlarda tespit edilmiştir. Kliniğimizde GDM taramasının 75 g OGTT ile yapılması eğilimi olduğundan bu verileri kıyaslayacak $100 \mathrm{~g}$ OGTT testi ile taranmış yeterli gebe sayısı yoktur. $\mathrm{Bu}$ sebeple bu çalışmada tek basamak ve iki basamak glukoz tarama testlerini karşılaştırma şansımız olmamıştır. Bu limitasyonu literatürde sunulan ülkemizde daha önce yapılmış çalışmalardan tartışma kısmında söz ederek yenmeye çalıştık.

\section{Sonuç}

Bu çalışma Türkiye'nin kuzeydoğusunda tek basamaklı tarama testi yapılan gebelerde GDM prevalansını araştıran ilk çalışmadır ve ülkenin farklı bölgelerinde yapılan çalışmalarda bulunan sonuçları karşılaştırma imkanı sağlamaktadır. Bu nedenle bu verilerin daha sonra devam eden çalışmalarla tekrar irdelenmesi gerekir. GDM prevalansının arttığı bir gerçektir. GDM'nin uygun taranması ve yönetimi maternal ve perinatal sonuçları iyileştirmektedir. Dikkatli bir değerlendirme ile ulusal kabul gören tarama yöntemi belirlenmelidir.

\section{Kaynaklar}

1. Cunningham FG. Diabetes. In: Cunningham FG, Gant NF, Leveno KJ, Gilstrap III LC, Hauth JC, Wenstrom KD (eds). Williams Obstetrics, 21th ed. New York: McGraw-Hill; 2001:1360-77.

2. American Diabetes Association. Gestational diabetes mellitus (position statement). Diabetes Care 2004;27( 2):88-90.

3. HAPO Study Cooperative Research Group, Metzger BE, Lowe LP, et al. Hyperglycemia and adverse pregnancy outcomes. N Eng J Med 2008;358(19):1991-2002.

4. Kuhl C. Glucose metabolism during and after pregnancy in normal and gestational diabetic woman. Acta Endocrinol 1995;79(4):709-19.

5. American College of Obstetricians and Gynecologists Committee Opinion No. 504. Screening and diagnosis of gestational diabetes mellitus. Obstet Gynecol 2011;118(3):751-3.

6. Ferrara A, Kahn H, Qesenberry C, Riley C, Hedderson M. An increase in the incidence of gestational diabetes mellitus: North California. Obstet Gynecol 2004;103(3):526-33.

7. American Diabetes Association. Standards of medical care in diabetes-2011. Diabetes Care 2011;34(1):4-10.

8. Carpenter MW, Coustan DR. Criteria for screening tests for gestational diabetes. Am J Obstet Gynecol 1982;144(7):768-73

9. Vandorsten JP, Dodson WC, Espeland MA, et al. NIH Consensus Development Conference: Diagnosing gestational diabetes mellitus. IH Consens State Sci Statements 2013;29(1):1-31.

10. Magee MS, Walden CE, Benedetti TJ, Knopp RH. Influence of diagnostic criteria on the incidence of gestational diabetes and perinatal morbidity. JAMA 1993;269(5): 609-15.

11. Tanir HM, Sener T, Gürer H, Kaya M. A ten-year gestational diabetes mellitus cohort at a university clinic of the mid-Anatolian region of Turkey. Clin Exp Obstet Gynecol 2005;32(4):241-4. 
12. Kösüs N, Kösüs A, Duran M, Turhan NO. Effect of number of abnormal oral glucose tolerance test (OGTT) values on birthweight in women with gestational diabetes. Indian J Med Res 2013;137(1):95-101.

13. Özyurt R, Aşıcıoğlu O, Gültekin T, Güngördük K, Boran B. The prevalence of gestational diabetes mellitus in pregnant women who were admitted to İstanbul Teaching and Research Hospital, Obstetric and Gynecology Department. JOPP Derg 2013;5(1):7-12.

14. Sevket O, Ates S, Uysal O, Molla T, Dansuk R, Kelekci S. To evaluate the prevalence and clinical outcomes using a one-step method versus a two-step method to screen gestational diabetes mellitus. J Matern Fetal Neonatal Med 2014;27(1):36-41.

15. International Association of Diabetes and Pregnancy Study Groups Recommendations on the Diagnosis and Classification of Hyperglycemia in Pregnancy. Diabetes Care Mar 2010;33(3):676-82.

16. Bodmer-Roy S, Morin L, Cousineau J, Rey E. Pregnancy outcomes in women with and without gestational diabetes mellitus according to the International Association of the Diabetes and Pregnancy Study Groups criteria. Obstet Gynecol 2012;120(4):746-52.

17. National Institute for Health and Clinical Excellence (NICE). Diabetes in Pregnancy: Management of Diabetes and its Complications from Pre-Conception to the Post-Natal Period. Clinical guideline no. 63. London: National Institute for Health and Clinical Excellence/National Collaborating Centre for Women's and Children's Health, 2008.

18. Brown CJ, Dawson A, Dodds R, et al. Report of the pregnancy and neonatal care group. Diabet Med 1996;13 (9 Suppl 4):43-53.

19. Committee opinion no. 504: Screening and diagnosis of gestational diabetes mellitus. Obstet Gynecol 2011;118(3):751-3.

20. Türk Endokrinoloji ve Metabolizma Derneği. Diabetes Mellitus ve Komplikasyonlarının Tanı, Tedavi ve İzlem Kılavuzu. Mayıs 2013.

21. Magee MS, Walden CE, Benedetti TJ, Knopp RH. Influence of diagnostic criteria on the incidence of gestational diabetes and perinatal morbidity. JAMA 1993;269(5):609-15. 